\title{
Simultaneous recording of oxytocin release, milk ejection and milk flow during milking of dairy cows with and without prestimulation
}

\author{
BY RUPERT M. BRUCKMAIER AND JÜRG W. BLUM \\ Institut für Tierzucht der Universität Bern, CH-3012 Bern, Schweiz
}

(Received 15 June 1995 and accepted for publication 15 September 1995)

\begin{abstract}
SUmmary. The effects of manual teat stimulation compared with stimulation by the liner of a conventional milking machine and the influence of milk ejection on the course of milk flow during the entire milking were investigated. Twelve cows were milked with or without prestimulation on three quarters and milk flow was recorded while intramammary pressure (IMP) was recorded in the left front quarter and blood samples for the determination of oxytocin (OT) were taken at $1 \mathrm{~min}$ intervals. OT concentrations increased very similarly in response to manual teat stimulation or liner stimulation and remained elevated during the entire milking procedure. Milk flow curves were generally bimodal without stimulation and not bimodal during milking after prestimulation. Milk yield was not significantly lower in milkings without than with stimulation, whereas machine-on time was prolonged and peak milk flow rate was reduced during milking without stimulation. Time to reach milk flow plateau, time to reach peak flow rate and IMP profiles were similar in both treatments if time was calculated from the start of stimulation. IMP increased similarly in response to manual or liner teat stimulation. In milkings with and without prestimulation IMP did not reach its maximum until the start of milking. In bimodal milk flow curves the second increase of milk flow occurred concomitantly with the start of IMP increase; ejection IMP generally occurred concomitantly with the milk flow plateau. In some cases during milking without prestimulation only small and transient OT release was observed. In response, IMP did not increase to its maximum and increased further in response to a stripping-related $\mathrm{O}^{\prime} \mathrm{T}$ release. During the course of milking IMP decreased slightly because of the emptying of the three milked quarters. After the end of milking, and with OT concentrations decreasing to the premilking values, IMP again decreased slightly to another plateau, probably owing to myoepithelial relaxation. Thus the course of milk ejection, i.e. the IMP profile, influenced milk removal markedly during early milking.
\end{abstract}

Only the small cisternal milk fraction is passively available for milk removal by simply surmounting the teat sphincter barrier (Bruckmaier et al. $1994 a$; Knight et al. 1994). The main portion of milk stored in the mammary gland before milking, the alveolar milk fraction, has to be shifted actively into the cisternal cavities via the milk ejection reflex to be available for milking. Alveolar milk ejection is induced by enhanced release of the neurohormone oxytocin (OT) from the posterior pituitary in response to tactile teat stimulation. Complete milk ejection requires elevated concentrations of OT above a threshold concentration (Schams et al. 1984; Gorewit \& Gassman, 1985) throughout the entire milking (Bruckmaier et al. 1994b). Premilking teat stimulation induces opportune alveolar milk ejection at the start of 
milking and therefore promotes continuous and rapid milk removal. In contrast, during milking without prestimulation milk ejection is induced only by the stimulation of the liner, and milk flow is in most cases transiently reduced or totally interrupted after removal of the cisternal milk until delayed alveolar milk ejection occurs (bimodal milk flow curve; Mayer et al. 1984; Bruckmaier et al. 1994a). However, to our knowledge the possibility that the renewed rise of milk flow in bimodal milk flow curves was related to the increase in intramammary pressure (IMP) associated with milk ejection has never been tested. Furthermore, it is generally believed that the stimulation provided by the conventional milking machine is less effective than manual or mechanical (by specially equipped milking machines) stimulation prior to the start of milk removal. The stimulatory efficiency of the conventional milking machine induced slightly restricted OT release as compared with manual prestimulation (Mayer et al. 1985). The effect on milk ejection could not be investigated by milk flow recording, because in milkings without prestimulation milk removal starts simultaneously with the commencement of stimulation.

The goal of this work was to compare the efficiency of manual teat stimulation and the stimulatory effect of the liner with respect to OT release, milk ejection and milk removal by simultaneous recording of OT, IMP and milk flow curve profiles. In addition, the dependence of milk flow curves on IMP profiles was investigated.

\section{MATERIALS AND METHODS}

Animals

Twelve experimental cows (Simmental $\times$ Red Holstein and Swiss Braunvieh) in the herd of the Swiss Federal Station for Animal Production (CH-1725 Posieux) were in months 3-9 of their second to sixth lactation. On the day before the start of the experiment total evening milk yield was $9 \cdot 5 \pm 0 \cdot 6 \mathrm{~kg}$. The cows were kept in tie stalls and fed on maize silage, hay and concentrates according to their individual production levels. During daily milking routine the animals were prestimulated by being given one to two forestripping squirts per teat and a short manual massage.

\section{Experimental design}

During the experiments three quarters were milked while IMP recording was performed in the unmilked left front quarter. The left front quarter was milked after the experiment. Experiments were performed during the usual milking time from 16.00 to 18.00 in the cows' familiar barn on two successive evenings, once with no prestimulation (i.e. the udder was not touched) and once with a 1 min manual prestimulation (massage of the teats) immediately before milking, following a crossover design. Milking was performed at $45 \mathrm{kPa}$ vacuum, a pulsation rate of 60 cycles/min and a 65:35 pulsator ratio using a 'Harmony' milking cluster (Alfa Laval Agri, S-147 21 Tumba, Sweden). Machine stripping was applied after milk flow dropped below $0.150 \mathrm{~kg} / \mathrm{min}$. IMP was recorded continuously from 2 min before milking until 5 min after the end of milking. Cows were catheterized for taking blood samples in one jugular vein on the first experimental day immediately after morning milking. Blood samples for the determination of OT concentrations were taken at $1 \mathrm{~min}$ intervals from $2 \mathrm{~min}$ before the start until $5 \mathrm{~min}$ after the end of milking.

Milk flow was continuously recorded using the Lactocorder ${ }^{\circledR}$ system (production: Werkzeug- und Maschinenbau Berneck AG, CH-9442 Berneck, Switzerland; distribution: Foss Electric A/S GmbH, D-22769 Hamburg, Germany). Measure- 
Table 1. Three quarter milking characteristics, one quarter intramammary pressure $(L M P)$, and oxytocin concentrations during milking with and without prestimulation

(Values are means \pm sem for $n=12$ )

\begin{tabular}{lcc}
\multicolumn{1}{c}{ Trait } & With stimulation & Without stimulation \\
'Total milk yield, kg & $7 \cdot 1 \pm 0 \cdot 7$ & $6 \cdot 5 \pm 0 \cdot 8$ \\
Machine-on time, min & $6 \cdot 0 \pm 0 \cdot 3$ & $7 \cdot 3 \pm 0 \cdot 3^{*}$ \\
Average flow rate, kg/min & $1 \cdot 2 \pm 0 \cdot 1$ & $0 \cdot 9 \pm 0 \cdot 1$ \\
Peak flow rate, kg/min & $2 \cdot 3 \pm 0 \cdot 2$ & $1 \cdot 9 \pm 0 \cdot 2^{*}$ \\
Time to reach plateau, min & $1 \cdot 9 \pm 0 \cdot 1$ & $1 \cdot 9 \pm 0 \cdot 2^{\mathrm{ST}}$ \\
T'ime to reach peak flow rate, min & $2 \cdot 4 \pm 0 \cdot 1$ & $2 \cdot 5 \pm 0 \cdot 2^{\mathrm{ST}}$ \\
Lag time, min & - & $1 \cdot 3 \pm 0 \cdot 1$ \\
Baseline IMP, kPa & $1 \cdot 7 \pm 0 \cdot 2$ & $1 \cdot 6 \pm 0 \cdot 2$ \\
Ejection IMP, kPa & $4 \cdot 9 \pm 0 \cdot 2$ & $4 \cdot 5 \pm 0 \cdot 3$ \\
lilP before stripping, kPa & $4 \cdot 3 \pm 0 \cdot 2$ & $4 \cdot 0 \pm 0 \cdot 2$ \\
IMP after stripping, kPa & $4 \cdot 5 \pm 0 \cdot 2$ & $4 \cdot 3 \pm 0 \cdot 2$ \\
IMP 5 min after end of milking, kPa & $4 \cdot 1 \pm 0 \cdot 2$ & $4 \cdot 0 \pm 0 \cdot 2$ \\
lnduction time, min & $1 \cdot 2 \pm 0 \cdot 1$ & $1 \cdot 3 \pm 0 \cdot 1^{\mathrm{ST}}$ \\
Ejection time, min & $1 \cdot 9 \pm 0 \cdot 1$ & $2 \cdot 0 \pm 0 \cdot 2^{\mathrm{ST}}$ \\
Oxytocin concn, ng/l & & \\
Premilking baseline & $3 \cdot 2 \pm 0 \cdot 9$ & $4 \cdot 4 \pm 0 \cdot 8$ \\
I-2 min after start of stimulation & $43 \cdot 9 \pm 12 \cdot 8$ & $37 \cdot 2 \pm 13 \cdot 0^{\mathrm{ST}}$ \\
I-0 min before stripping & $33 \cdot 4 \pm 8 \cdot 3$ & $33 \cdot 6 \pm 6 \cdot 7$ \\
I-2 min after start of stripping & $35 \cdot 8 \pm 4 \cdot 3$ & $36 \cdot 2 \pm 8 \cdot 1$ \\
$4-5$ min after end of milking & $10 \cdot 3 \pm 1 \cdot 5$ & $9 \cdot 5 \pm 1 \cdot 6$
\end{tabular}

ST To compare the effects of the 1 min prestimulation and stimulation by the liner, these traits were calculated from the start of prestimulation and from the start of milking in milkings with and without stimulation respectively.

* Means with and without stimulation were significantly different: $P<0.05$.

ments were carried out as described by Bruckmaier et al. (1995). In addition, 'time to reach plateau' was measured: the time until the slope of the milk flow curve (in bimodal curves of the second peak) was $<1.0 \mathrm{~kg} \mathrm{~min}{ }^{-2}$. 'Lag time' was defined, in bimodal milk flow curves only, as the time from the start of milking until milk flow started to increase for the second time.

IMP was measured by a strain gauge system via a cannula through the left front quarter teat channel and was continuously conveyed to a strip chart recorder as described by Bruckmaier et al. (1994b). 'Induction time' was the time from the start of stimulation until IMP started to increase; 'ejection time' was the time from the start of stimulation until IMP reached its maximum. Plasma OT concentrations were determined by radioimmunoassay (Bruckmaier et al. 1996).

\section{Statistical evaluation}

Results are presented as means $\pm s E M$. Within-animal differences between treatments and differences in corresponding time points of IMP and milk flow profiles were tested for significance by paired $t$ test using the UNIVARIATE procedure of the SAS program package (SAS, 1993).

\section{RESULTS}

\section{Milking and intramammary pressure characteristics}

The course of milk flow was never bimodal during milking after prestimulation and bimodal without stimulation (Figs 1 and 2). Total milk yield from three quarters (Table 1) was slightly but not significantly higher with than without prestimulation. 

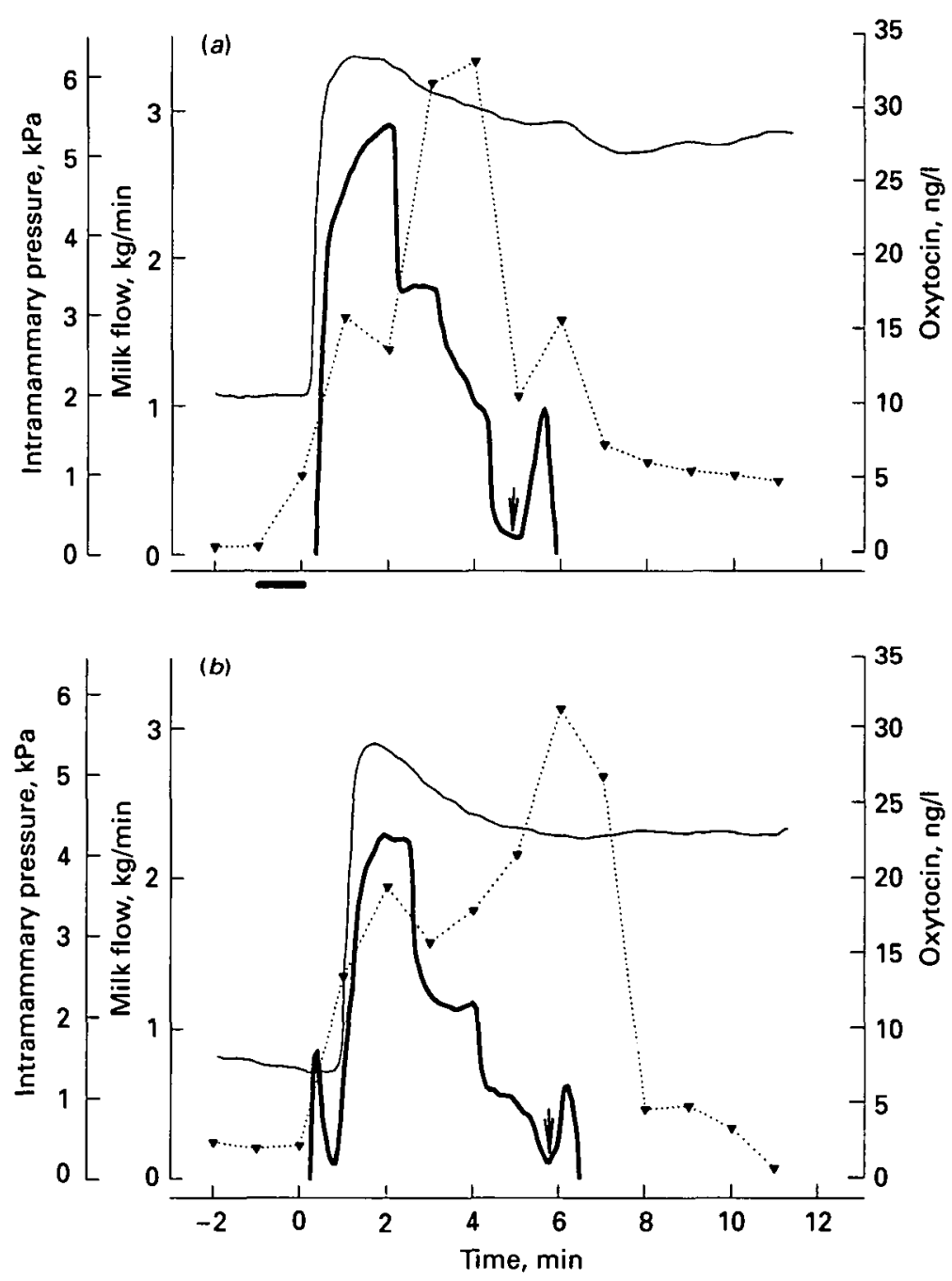

Fig. 1. $\nabla$, Oxytocin concentrations; - - , intramammary pressure and - milk flow from three quarters of an individual cow with steadily increasing oxytocin concentrations during milking $(a)$ with and $(b)$ without manual prestimulation. 0 , Start of milking; - prestimulation; $\$$, start of stripping.

However, machine-on time (Table 1; Figs 1 and 2) was significantly prolonged without stimulation. Average flow rates (Table 1) were not significantly different with and without prestimulation. However, peak flow rate (Table 1) was significantly higher during milking with than without stimulation. Exceptionally, peak flow rate was even higher without than with prestimulation (Fig. 2). Time to reach milk flow plateau and time to reach peak flow rate were delayed by $1 \mathrm{~min}$ in milkings without prestimulation, but were similar in both treatments if time was calculated not from the start of milking but from the start of stimulation (Table 1).

Baseline IMP (Table 1) was similar in both treatments, whereas ejection IMP (Table 1) was not significantly higher with than without stimulation $(P=0 \cdot 08)$. During the course of milking IMP decreased slightly $(P<0.05)$ in both treatments (Figs 1 and 2). However, if the three other quarters were not milked during IMP recording, the IMP remained constant at its maximum until several minutes after teat stimulation (results not shown). During and within $1 \mathrm{~min}$ after stripping IMP 

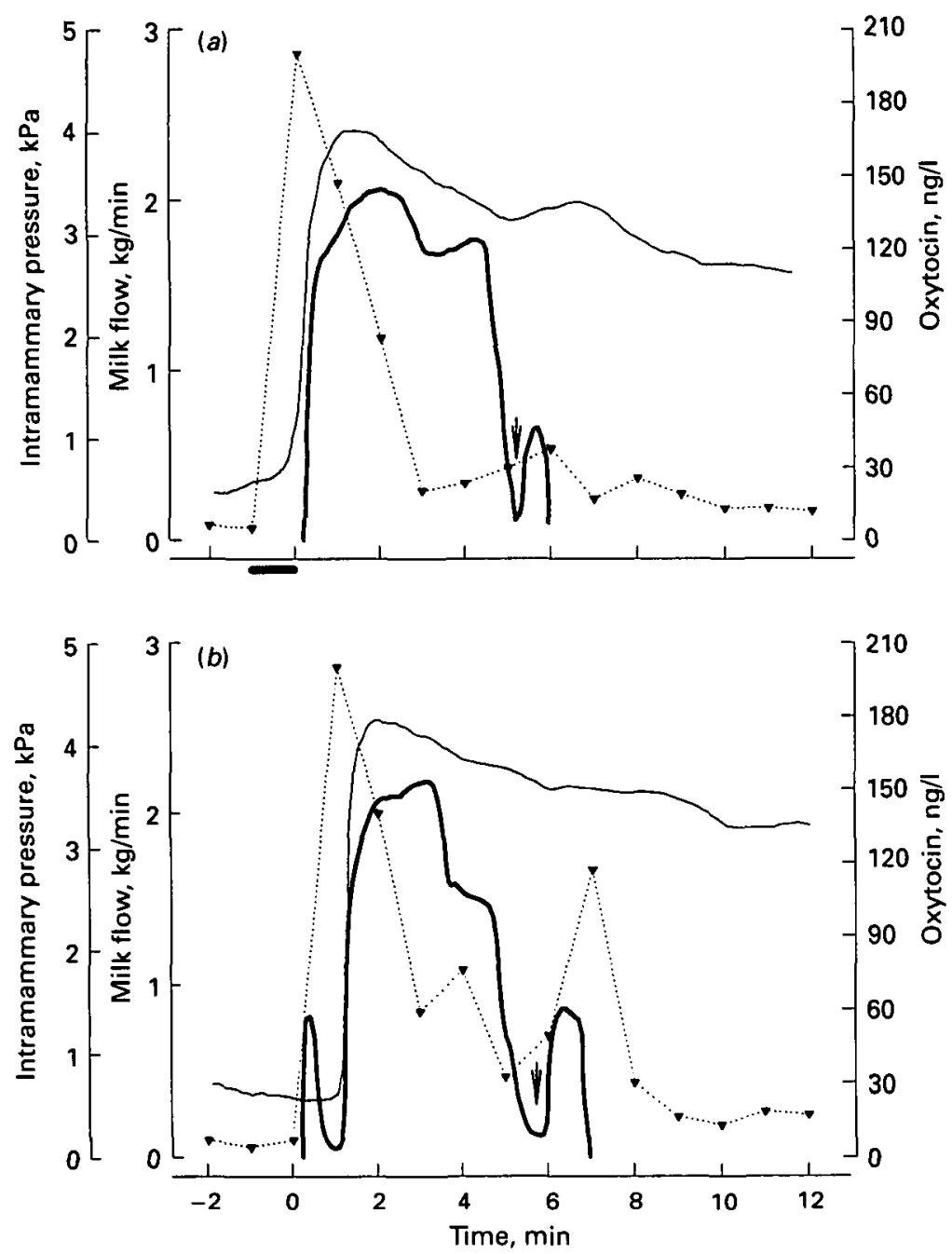

Fig. 2. $\nabla$, Oxytocin concentrations; - intramammary pressure and - , milk flow from three quarters of an individual cow with peak oxytocin concentrations during early milking $(a)$ with and $(b)$ without manual prestimulation. 0 , Start of milking; - , prestimulation; $\psi$, start of stripping.

remained constant (Figs 1 and $2 b$ ) or increased slightly (Fig. 2a). Within 5 min after the end of milking IMP decreased to a slightly lower level $(P<0 \cdot 05$; Figs $1 a$ and $2 a, b)$.

Time to reach milk flow plateau was congruent with ejection time measured in IMP profiles $(P=0 \cdot 7)$, and lag time until milk flow increased for the second time in bimodal milk flow curves (without stimulation) was congruent with induction time $(P=0 \cdot 6)$, although neither was significant.

\section{Oxytocin concentrations}

Premilking OT concentrations (Table 1) were low and similar in both treatments. Within 1-2 min after the start of stimulation (Table 1), i.e. 1 min later in milkings without than with prestimulation, OT increased similarly in both. Thus, early milking IMP increase never occurred before the OT rise. Although the hormone profiles were of different shape, OT remained elevated during the entire milking as compared with baseline concentrations $(P<0.05$; Table 1 , Figs 1 and 2$)$. 


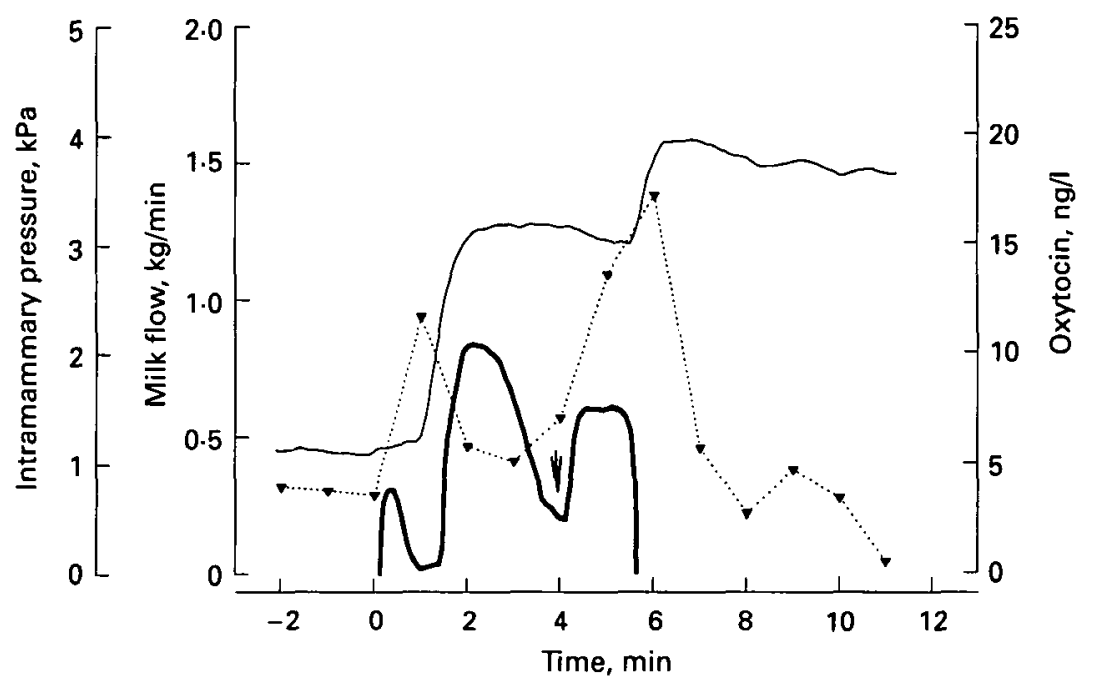

Fig. 3. $\nabla$, Oxytocin concentrations; __, intramammary pressure and - , milk flow from three quarters of an individual cow with a small and transient oxytocin release during early milking without manual prestimulation. 0 , Start of milking; $\psi$, start of stripping.

Nevertheless, the early milking IMP increase and further course of IMP during milking was similar if OT continuously increased during milking (Fig. 1) and if OT immediately increased to its maximum and then decreased during milking (Fig. 2). Before stripping (Table 1) mean OT concentration had again slightly decreased and then increased slightly during stripping in some but not all animals (not significant). After the end of milking OT decreased towards basal concentration (Table 1, Figs 1 and 2).

\section{Special observations}

While in most animals milk yields were comparable with and without prestimulation, two animals yielded only $32 \%$ (Fig. 3 ) and $47 \%$ without stimulation of the milk yield with prestimulation. In these milkings OT release during early milking was only small and transient and IMP did not increase up to its maximum (Fig. 3). Only during stripping was OT released more markedly and IMP increased further. These milkings were characterized by an abnormally high stripping yield although stripping was stopped after $\sim 1 \mathrm{~min}$.

\section{DISCUSSION}

The occurrence of non-bimodal milk flow curves during milking with prestimulation and bimodal milk flow curves without stimulation have already been described (Mayer et al. 1984; Bruckmaier et al. 1995). Bimodal milk flow curves have been explained by delayed availability of the alveolar milk after removal of the cisternal milk fraction. We have now shown that the second rise of milk flow in milkings without prestimulation started at exactly the same time as the IMP increase within the teat, thus indicating alveolar milk ejection (i.e. lag time $=$ induction time). In addition, in both non-bimodal and bimodal milk flow curves the time to reach milk flow plateau was consistent with the time at which IMP reached its maximum (ejection time). The influence of the increasing IMP and hence milk ejection on the course of milk flow during early milking was therefore quite obvious. Interestingly, 
milk flow usually increased slightly further to reach peak flow rate although ejection IMP had already been reached. Obviously factors other than IMP, possibly teat sphincter and teat smooth muscle tone, determine peak milk flow rate to some extent. Nevertheless, we have shown previously that IMP in milked quarters decreases rapidly after the start of milking although milk flow rate remained at its plateau value (Pfeilsticker et al. 1995).

In some milkings there was a slight IMP increase in response to stripping, i.e. in response to an additional release of OT more milk could still be shifted into the cistern. This was possibly due to the relaxation of the milked quarters described by Pfeilsticker et al. (1995) which caused a fall of IMP during milking and thus the conditions necessary for a new IMP rise.

Owing to a 1 min delay of teat stimulation, OT release was delayed in milkings without prestimulation. However, if time was calculated from the start of stimulation in both treatments, OT release was only slightly and not significantly less in milkings without prestimulation. The stimulatory effect of the liner on the OT release was therefore comparable with that of manual teat stimulation. During the further course of milking, mean OT decreased slightly in milkings without and with stimulation although in individual cases OT increased during the entire milking period without any effect on IMP or milk flow. This finding supports the existence of a threshold concentration of $\mathrm{O} T$ for the induction of maximal milk ejection. It was shown previously that milking related OT release generally varies considerably and has no influence on the milk flow curve (Schams et al. 1984) or ejection IMP (Mayer et al. 1991). Partial milk ejection could be measured as partial IMP increase. Possibly some exceptional individuals need a more intense stimulus than that provided by the conventional milking machine. Emotional disturbance also seems a possible influence because under our experimental conditions only three quarters were milked, IMP was measured concomitantly and blood samples were taken from the jugular vein. Partly disturbed milk ejection has been shown to be associated with delayed, reduced and transient OT release (Bruckmaier et al. 1996). Transient OT release evoking partial milk ejection has also been demonstrated in response to teat cannulation (Mayer et al. 1991). Nevertheless, although the existence of a threshold level for O'T to elicit a maximum milk ejection was again confirmed in this investigation, it was also shown that in cases with reduced (below the threshold) or transient OT release this may cause only partial milk ejection during machine milking.

It was shown previously that the conventional milking machine elicits the same O'T release as manual prestimulation (Sagi et al. 1980; Gorewit \& Gassman, 1985) although peak concentrations of OT seemed to occur earlier during milking with manual prestimulation (Sagi et al. 1980). Nevertheless, vibration or positive pressure mechanical prestimulation was shown to cause no greater OT release than manual stimulation (Mayer et al. 1985).

Since we found no significant difference of ejection IMP in the two treatments, prolonged machine-on time and reduced peak flow rate in milkings without stimulation must have been caused solely by the delayed induction of the milk ejection reflex when teat stimulation started only with the start of milking. The difference in machine-on time and peak flow rate between the treatments is obviously caused by two factors: the delayed milk ejection leads to delayed availability of the main milk fraction and therefore to the well known interruption of milk flow, and the milking vacuum is carried on into the mammary gland during the period of low milk flow in bimodal milk flow curves. As a consequence mammary ducts collapse and the teatcups climb, which may cause reduced milk ejection and milk flow rates. 
During the course of milking, IMP in the unmilked quarter decreased slightly but significantly. This effect did not occur if all quarters remained unmilked. Thus the pressure decrease during milking was probably caused by the relaxation of the three surrounding quarters while they were evacuated. At least the cisternal cavities of the three milked quarters were almost emptied when alveolar milk ejection occurred.

After the end of milking, when OT concentrations decreased toward premilking values, IMP decreased again-slightly, but significantly. This confirms the previously reported slight decrease of IMP some minutes after OT injection when circulating OT concentrations decrease again toward basal levels (Bruckmaier et al. 1994b). Our thesis is that ejection IMP is composed of the effect of the 'liquid column' and a 'myoepithelial contraction' component. With the decrease of OT concentrations toward basal values, the myoepithelial contraction and hence the corresponding pressure component disappears.

In conclusion, the course of milk ejection, indicated by the IMP, determined the course of milk flow mainly during the early period of milking. Simultaneous recording of milk flow and IMP is potentially an excellent method of checking the stimulatory potency of different mechanical prestimulation systems as they are incorporated in various milking machines.

We are indebted to Mr F. Jans and the Swiss Federal Research Station of Animal Production, CH-1725 Posieux for providing us with the animals. The expert assistance of Dr H. Hammon, Mrs D. Hugi, Mr H.-U. Pfeilsticker and Mrs Y. Zbinden during animal experiments and laboratory work is greatly appreciated. We thank Dr T. Hoefelmayr, Werkzeug- und Maschinenbau Berneck AG, and Dr H. Göft, Foss Electric A/S GmbH for providing the Lactocorder ${ }^{\circledast}$ system.

\section{REFERENCES}

Bruckmaier, R. M., Pfellsticker, H.-U.\& Blus J. W. 1996 Milk yield, oxytocin and $\beta$-endorphin gradually normalize during repeated milking in unfamiliar surroundings. Journal of Dairy Research 63 191-200

Bruckmaier, R. M., Rothenanger, E. \& Blum, J. W. 1994 a Measurement of mammary gland cistern size and determination of the cisternal milk fraction in dairy cows. Milchwissenschaft 49 543-546

Bruckmaier, R. M., Rothenanger, E. \& Blum, J. W. 1995 Milking characteristics in dairy cows of different breeds from different farms and during the course of lactation. Zeitschrift für Tierzuchtung und Zuchtungsbiologie 112 293-302

Bruckmaier, R. M., Schams, D. \& Blum, J. W. $1994 b$ Continuously elevated concentrations of oxytocin during milking are necessary for complete milk removal in dairy cows. Journal of Dairy Research 61 323-334

Gonewir, R. C. \& Gassman, K. B. 1985 Effects of duration of udder stimulation on milking dynamics and oxytocin release. Journal of Dairy Science 68 1813-1818

Knight, C. H., Hinst, D. \& Dewhurst, R. J. 1994 Milk accumulation and distribution in the bovine udder during the interval between milkings. Journal of Dairy Research 61 167-177

MAYeR, H., BrUckmaler, R. M. \& Schams, D. 1991 Lactational changes in oxytocin release, intramammary pressure and milking characteristics in dairy cows. Journal of Dairy Research 58 159-169

Mayer, H., Schams, D., Worstorff, H. \& Prokopp, A. 1984 Secretion of oxytocin and milk removal as affected by milking cows with and without manual stimulation. Journal of Endocrinology 103 355-361

MAYER, H., WORSTORFF, H., Schams, D. \& KLEIN, M. 1985 Secretion of oxytocin and milking characteristics in cows as affected by several modes of tactile teat stimulation. Milchwissenschaft 40 1-5

Pfeilsticker, H.-U., Bruckmaier, R. M. \& BluM, J. W. 1995 Interruption of machine milking in dairy cows: effects on intramammary pressure and milking characteristics. Journal of Dairy Research 62559.566

Sagi, R., Gorewit, R. C., Merrill, W. G. \& Wilson, D. B. 1980 Premilking stimulation effects on milking performance and oxytocin and prolactin release in cows. Journal of Dairy Science $63800-806$

SAS 1993 SAS User's Guide: Statistics. Cary, NC: SAS Institute

Schams, D., Mayer, H., Prokopp, A. \& Worstorff, H. 1984 Oxytocin secretion during milking in dairy cows with regard to the variation and importance of a threshold level for milk removal. Journal of Endocrinology $102337-343$ 